\title{
The links between diabetes mellitus and amyotrophic lateral sclerosis
}

\author{
Rosario Vasta ${ }^{1}$ (D) Fabrizio D'Ovidio ${ }^{1}$ - Giancarlo Logroscino ${ }^{2,3} \cdot$ Adriano Chiò $^{1,4}$
}

Received: 15 October 2020 / Accepted: 28 January 2021 / Published online: 5 February 2021

(C) The Author(s) 2021

\begin{abstract}
ALS etiology and prognostic factors are mostly unknown. Metabolic diseases and especially diabetes mellitus (DM) have been variously related to ALS. However, pieces of evidence have been variegated and often conflicting so far. This review aims to give an overview of recent contributions focusing on the relationship between DM and ALS. DM seems to reduce the risk of developing ALS if diagnosed at a younger age; conversely, when diagnosed at an older age, DM seems protective against ALS. Such a relationship was not confirmed in Asian countries where DM increases the risk of ALS independently of the age of onset. Interestingly, DM does not affect ALS prognosis, possibly weakening the potential causal relationship between the two diseases. However, since most studies are observational, it is difficult to state the exact nature of such a relationship and several hypotheses have been made. A recent study using Mendelian randomization suggested that DM is indeed protective against ALS in the European population. However, these analyses are not without limits and further evidence is needed. DM is usually the core of a larger metabolic syndrome. Thus, other metabolic changes such as dyslipidemia, body mass index, and cardiovascular diseases should be collectively considered. Finally, hypermetabolism usually found in ALS patients should be considered too since all these metabolic changes could be compensation (or the cause) of the higher energy expenditure.
\end{abstract}

Keywords Amyotrophic lateral sclerosis $\cdot$ Epidemiology $\cdot$ Diabetes mellitus $\cdot$ Metabolic syndrome

\section{Introduction}

Amyotrophic lateral sclerosis (ALS) is a neurodegenerative disease affecting motor neurons. It causes the paralysis of voluntary muscles, leading to death, usually for respiratory failure, in 2 to 4 years from symptoms onset [1]. In most cases, the etiology of ALS is unknown but it is thought to involve both genetic and environmental factors [1]. The difficulty in identifying risk factors for ALS reflects the complexity of the

Rosario Vasta and Fabrizio D'Ovidio contributed equally to this work.

Rosario Vasta

sarovasta@gmail.com

1 ALS Center, 'Rita Levi Montalcini' Department of Neuroscience, University of Turin, Turin, Italy

2 Department of Clinical Research in Neurology, Center for Neurodegenerative Diseases and the Aging Brain, University of Bari "Aldo Moro", "Pia Fondazione Cardinale G. Panico", Tricase, Italy

3 Department of Basic Medical Sciences, Neuroscience and Sense Organs, University of Bari “Aldo Moro”, Bari, Italy

4 Neurology 1, Azienda Ospedaliero Universitaria Città della Salute e della Scienza, Turin, Italy disease, and a more systemic approach may be needed to unravel significant associations with genetic and environmental factors [2].

Diabetes mellitus (DM) is a chronic disease caused by dysfunctional use, or the lack, of insulin and resulting in impaired blood glucose regulation. DM can be classified as type 1 (T1DM) and type 2 (T2DM) depending on the deficient insulin production or on the body's ineffective use of insulin, respectively [3]. DM has an $8.5 \%$ prevalence among the adult population; in 2014, 422 million people worldwide were affected by DM [4].

Given the hypermetabolism that accompanies ALS [5], the association with concomitant metabolic diseases such as DM, hypertension, dyslipidemia, and obesity has been diffusely studied [6]. In this review, we aimed to examine all contributions focused on the association between DM and ALS.

\section{Methods}

We performed a review of peer-reviewed articles in full and only in English. The searching process was performed in PubMed MEDLINE, using the following search formula: 
("ALS" OR "Amyotrophic Lateral Sclerosis" OR "motor neuron disease" OR "Lou Gehrig disease") AND ("diabetes" OR "Diabetes mellitus" OR "Glucose intolerance" OR "insuline" OR "hyperglycemia"). The review design was not restricted by study design. The eligible criteria were firstly evaluated by abstract readings and subsequently by reading the remaining articles. References of the collected published studies were also considered. Because of the high number of articles retrieved, searching was restricted to a 7-year period, starting from January 1, 2013, and updated to December 31, 2019. Given the diversity of study designs and measures of associations, a narrative review was performed.

\section{Results}

A total of 230 articles were identified. Of these, 35 articles were considered pertinent for the narrative analysis.

The more frequent article types were cohort studies $(n=$ $10)$ followed by case-control studies $(n=7)$, reviews $(n=5)$, and letters $(n=4)$. Editorials $(n=3)$, cellular $(n=2)$, and animal studies $(n=2)$ were also retrieved, together with 1 observational cohort study protocol and 1 randomized clinical trial (Table 1).

Studies not reporting an explicit link between DM and ALS were not included in this count.

However, other contributes were also examined in order to better understand the mechanisms behind the association between DM and ALS.

Because of the high diversity of these results, the review was structured into thematic sections.

\section{Diabetes mellitus as a risk factor for ALS}

In the USA, a case-control study enrolling 1288 cases and 7561 controls reported a protective role of DM as antecedent condition of ALS (odds ratio (OR) 0.47 ; $95 \%$ confidence intervals (CI) 0.38-0.58) [7].

In a Swedish nested case-control study which enrolled 224 ALS cases and 1437 controls individually matched for age, sex, and area of residence, DM was found to be protective against ALS but only among subjects above 70 years (OR $0.71,95 \%$ CI $0.57-0.89$ in the 70-79 age class and OR $0.56,95 \%$ CI $0.40-0.78$ in the $>80$ age class), whereas below 50 years DM was associated with an increased ALS risk (OR 3.15, 95\% CI 1.40-7.08) [8]. However, two editors' letters pointed out the lack of adjustment of body mass index (BMI) in the analyses, the exclusion of patients with T1DM, and the role of drug medication on the association between T2DM and ALS [9, 10].

Similar results were obtained by a Danish nested casecontrol study, which enrolled 3650 ALS patients and 365,000 controls extracted from the Danish National
Register system, matched for sex and age [11]. The study reported an overall inverse association between DM and ALS (OR 0.61, 95\% CI 0.46-0.80), with a protective effect of DM above 61 years (at 65 years old OR $0.65,95 \%$ CI 0.50 0.85 ) and a non-significant increased risk below 51 years (at 35 years old OR 1.68, 95\% CI 0.75-3.75). Another cohort study was conducted in Asia, enrolling 615,492 diabetic subjects and 614,835 subjects as comparison cohort matched for age and sex followed up from 2000 to 2008 [12]. Authors found an overall significant hazard ratio (HR) of $1.35(95 \%$ CI 1.10-1.67), with sex and age as modifiers of the association: DM was significantly and positively associated with ALS only for men younger than 65 years old (HR 1.67; 95\% CI 1.18-2.36).

Finally, a recent retrospective cohort study was conducted in Taiwan using administrative data and considering patients who had a T2DM diagnosis during the 2000-2013 period ( $n=$ $2,135,427$ ) compared to a matched sample from the unexposed population. The risk of developing ALS did not differ in patients with prior T2DM (HR 0.87, 95\% CI 0.70-1.07, $p=$ $0.190)$. However, when considering the age at T2DM diagnosis, DM resulted negatively associated with ALS in patients whose age was $\geq 55$ years (HR $0.72,95 \%$ CI $0.55-0.95, p=$ $0.019)$ [13].

In a large Dutch case-control study, DM inverse relationship with ALS resulted slightly not significant (OR 0.72, 95\% CI 0.51-1.01) [14].

Such opposite risk based on age at T2DM diagnosis was not confirmed by a recent Italian cohort study, which followed 727,977 residents in Turin from 1996 to 2014 and included a time-dependent analysis. DM resulted to be significantly associated with a decreased risk of ALS (HR 0.30, 95\% CI 0.19-0.45), without significant differences in risk by sex, age, and ALS phenotype [15].

The inverse relationship between DM and ALS depending on age at DM diagnosis was underlined in a recent editorial [16]. The author also argued that mixed ethnic groups showed a lower ALS risk than people of African or European ancestry even when they live within the same geographic area, thus suggesting a possible role of genetics in such differences [16].

All these studies focused on T2DM. A British study assessing the risk of ALS for people affected by each of a range of autoimmune diseases showed that T1DM did not confer an increased risk of developing ALS. However, ALS risk resulted significantly increased for people aged less than 30 years at first diagnosis of T1DM (relative risk (RR) 3.94; 95\% CI 1.84-7.50) [17]. A previous study distinguished T1DM and T2DM only based on the age at diagnosis, respectively under and above 30 years age [8]. Both types resulted to be inversely associated with ALS, but only T2DM was significantly associated (OR $0.65,95 \%$ CI $0.52-0.79$ ).

An editorial based on this study highlighted the opposite effect of T1DM and T2DM in the developing ALS, and the 
Table 1 Articles included in the review

\begin{tabular}{|c|c|c|c|c|c|}
\hline Reference & First author, year & Type of study & Nation & $\begin{array}{l}\text { Diabetes as risk/ } \\
\text { prognostic factor }\end{array}$ & Effect size \\
\hline$[6]$ & Brito, 2019 & Review & - & Prognosis & - \\
\hline$[7]$ & Mitchell, 2015 & Case-control & USA & Risk & OR 0.47 (95\%CI (0.38-0.58)) \\
\hline$[8]$ & Mariosa, 2015 & Nested case-control & Sweden & Risk & $\begin{array}{l}\text { Overall: OR } 0.79(0.68-0.91) \\
<50 \text { age class: OR } 3.15(1.40-7.08) \\
70-79 \text { age class: OR } 0.71,95 \% \text { CI } 0.57-0.89 \\
\geq 80 \text { age class: OR } 0.56,95 \% \text { CI } 0.40-0.78\end{array}$ \\
\hline$[9]$ & Kawada, 2016 & Letter to the Editor & - & - & - \\
\hline$[10]$ & Mariosa, 2016 & Letter to the Editor & - & - & - \\
\hline$[11]$ & Kioumourtzoglou, 2015 & Nested case-control & Denmark & Risk & $\begin{array}{l}\text { Overall: OR } 0.61 \text { ( } 95 \% \text { CI } 0.46-0.80) \\
\text { At } 65 \text { years old: OR } 0.65(95 \% \text { CI } 0.50-0.85) \\
\text { At } 35 \text { years old: OR } 1.68 \text { ( } 95 \% \text { CI } 0.75-3.75)\end{array}$ \\
\hline$[12]$ & Sun, 2015 & Cohort & Taiwan & Risk & $\begin{array}{l}\text { Overall: HR } 1.35 \text { (95\% CI 1.10-1.67) } \\
\text { Men < } 65 \text { years old: HR 1.67; 95\% CI 1.18-2.36 }\end{array}$ \\
\hline$[13]$ & Tsai, 2019 & Cohort & Taiwan & Risk & $\begin{array}{l}\text { Overall: HR } 0.87,95 \% \text { CI } 0.70-1.07 \\
\geq 55 \text { years age class: HR } 0.72,95 \% \text { CI } 0.55-0.95\end{array}$ \\
\hline$[14]$ & Seelen, 2014 & Case-control & Netherlands & Risk & OR $0.72,95 \%$ CI $0.51-1.01$ \\
\hline$[15]$ & D’Ovidio, 2018 & Cohort & Italy & Risk & HR $0.30,95 \%$ CI $0.19-0.45$ \\
\hline$[16]$ & Logroscino, 2015 & Editorial & - & - & - \\
\hline$[17]$ & Turner, 2013 & Cohort & England & Risk & RR $3.94 ; 95 \%$ CI $1.84-7.50$ \\
\hline$[18]$ & Jawaid, 2015 & Editorial & - & - & - \\
\hline$[19]$ & Korner, 2013 & Cohort & Germany & Prognosis & $\begin{array}{l}\text { On survival: HR } 1.11,95 \% \text { CI } 0.76-1.60 \\
\text { On progression: HR } 1.07,95 \% \text { CI } 0.74-1.57\end{array}$ \\
\hline$[20]$ & Paganoni, 2015 & Cohort & RCTs & Prognosis & Not provided \\
\hline$[21]$ & Jawaid, 2015 & Letter to the Editor & - & - & - \\
\hline$[22]$ & Paganoni, 2015 & Letter to the Editor & - & - & - \\
\hline$[23]$ & Mandrioli, 2018 & Cohort & Italy & Prognosis & HR $1.11,95 \%$ CI $0.93-1.33$ \\
\hline$[24]$ & Moglia, 2017 & Cohort & Italy & Prognosis & HR $1.05,95 \%$ CI $0.78-1.42$ \\
\hline$[25]$ & Wei, 2017 & Cohort & China & Prognosis & $\begin{array}{l}\text { HbA1c between } 5.7 \% \text { and } 6.4 \%: \text { HR } 1.40 \\
\text { HbA1c }>6.5 \%: \text { HR } 2.06\end{array}$ \\
\hline$[26]$ & Zhang, 2019 & Cohort & China & Prognosis & HR $0.84,95 \%$ CI $0.68-1.30$ \\
\hline$[27]$ & Hollinger, 2016 & Case-control & & Prognosis & Not provided \\
\hline$[28]$ & Zeng, 2019 & Case-control & Europe/Asia & Risk & $\begin{array}{l}\text { Europe: OR } 0.93,95 \% \text { CI } 0.88-0.99 \\
\text { Asia: OR } 1.17,95 \% \text { CI } 0.93-1.47\end{array}$ \\
\hline$[29]$ & Lim, 2014 & Animal study & - & - & - \\
\hline$[30]$ & Joardar, 2017 & Review & - & - & - \\
\hline$[31]$ & Rauskolb, 2017 & Review & - & - & - \\
\hline$[32]$ & Shi, 2019 & Animal study & - & - & - \\
\hline$[33]$ & Araki, 2019 & Cellular study & - & - & - \\
\hline$[34]$ & Jawaid, 2018 & Editorial & - & - & - \\
\hline$[35]$ & Pfeiffer, 2019 & Case-control & USA & - & - \\
\hline$[36]$ & Walker, 2016 & Protocol & UK & - & - \\
\hline$[37]$ & Liu, 2015 & Review & - & - & - \\
\hline$[38]$ & Liu, 2015 & Cellular study & - & - & - \\
\hline [39] & Wills, 2014 & $\mathrm{RCT}$ & - & - & - \\
\hline [40] & Herskovits, 2013 & Review & - & - & - \\
\hline
\end{tabular}

Studies not reporting an explicit link between DM and ALS are not included in this table. OR, odds ratio; $R R$, relative risk; $H R$, hazard ratio; $95 \% C I, 95 \%$ confidence intervals; $R C T$, randomized clinical trial; HbA1c, glycated hemoglobin 
role of BMI correlated with both types of DM, and also with ALS onset and survival [18].

\section{Diabetes mellitus as a prognostic factor for ALS}

A German study reconstructed comorbidities of a cohort of 514 ALS patients in order to estimate their effect on survival and disease progression, revealing that DM did not significantly affect both survival (considered as the interval from ALS diagnosis to death, tracheostomy, or censoring, HR $1.11,95 \%$ CI $0.76-1.60$ ) and progression (estimated by using the logarithmic ALSFRS-R score ratio as the dependent variable, HR 1.07, 95\% CI 0.74-1.57) [19]. A study including 1322 patients from 6 ALS clinical trials showed that survival was not different from DM to non-DM patients $(p=0.98)$ [20]. Regarding this study, a letter to the editor [21] and a reply [22] were written in order to better clarify the methodological differences between this and another American study [41].

Even in two recent Italian studies, DM was not significantly associated with ALS survival. The first one was performed in 13 Italian ALS centers from 2009 to 2013 and enrolled 2354 incident ALS patients. The authors reported a nonsignificant effect of DM on ALS survival (HR 1.11, 95\% CI 0.93-1.33) [23]. In the second population-based cohort study, 650 ALS incident patients were recruited and T2DM was not associated with survival (HR 1.05, 95\% CI $0.78-1.42 ; p=$ 0.84) [24].

A Chinese cohort study recruiting 450 ALS patients indicated that higher levels of hemoglobin A1c (HbA1c) at diagnosis were significantly associated with a higher risk of mortality (HR 1.40 for $\mathrm{HbAl}$ c between 5.7 and $6.4 \%$ and HR 2.06 for HbA1c $>6.5 \% ; p$ trend $=0.01$ ) [25]. Finally, in another study, survival was not significantly longer in the diabetic ALS patients group when compared to non-DM patients (HR 0.84, 95\% CI 0.68-1.30; $p=0.617$ ) [26].

Notably, a recent systematic review pointed out that pieces of evidence are not sufficient to establish a link between metabolic alterations and ALS progression [6].

DM was also found to delay ALS onset. A case-control study focusing on antecedent conditions included 1439 ALS patients distinguished in 600 patients without antecedent conditions and 839 patients with at least one antecedent condition. DM was found to be significantly associated with both later ages of ALS onset $(p<0.0001)$ and shorter disease duration $(p$ $<0.0069$ ) [27]. Same results were reported also in a previous study, which evaluated 2371 ALS patients and where DM was associated with a 4-year later onset of ALS (56.3 years old for non-DM ALS patients and 60.3 years old for diabetic ALS patients, $p<0.05$ ) [41]. Such delay was confirmed by a Chinese study including a total of 2562 ALS which found, after adjusting for sex and site of onset, that patients with pre- morbid DM showed a 4.4-year delay in the ALS onset (57.0 \pm 9.6 vs $52.6 \pm 10.3$ years; $p<0.001$ ) [26].

\section{Genetic links}

In DM, hereditary components are estimated to range between 20 and $80 \%$ [42]. The first genes revealed were $C A P N 10$ and $T C F 7 L 2$, but other genes were considered candidates to play a significant role in the pathogenesis of T2DM, such as $P P A R G$, $I R S 1$, and IRS-2, KCNJ11, WFS1, HNFIA, HNF1B, and HNF4A [42].

Over the past 20 years, several gene mutations in ALS have been identified, including both major genes (such as $S O D 1$, TARDBP, FUS, OPTN, VCP, UBQLN2, C9ORF72, and $P F N 1)$ and several other minor genes [43]. Among minor genes, SH2B3 and ATXN2 were found to be associated with both autoimmune and neurodegenerative diseases [44]. ATXN2 plays an important role for ALS since intermediatelength polyQ expansions (27-33 glutamines) in this gene were found to be significantly associated with the ALS risk [45]. Furthermore, a Turkish study, in which genomes of 158 sporadic and 78 familial ALS patients were compared with those of 420 healthy controls, found that 31-32 polyQ repeats in the ATXN2 gene were associated with a risk of ALS in $1.7 \%$ of the Turkish ALS cohort $(p=0.0172)$ and that a significant association of a 136-kb haplotype block across ATXN2 and SH2B3 genes was found in $19.4 \%$ of a subset of the ALS cohort and in $10.1 \%$ of the controls $(p=0.0057$, OR 2.23), an indication that $A T X N 2$ and $S H 2 B 3$ variants may interact in modulating the disease pathway [46].

A recent study analyzed GWAS data from two large European and Asian samples $(\sim 660,000$ individuals for T2DM and $\sim 81,000$ individuals for ALS in the European population, and $\sim 191,000$ individuals for T2DM and 4100 individuals for ALS in the East Asian population). Adopting the Mendelian randomization (MR) approach, authors demonstrated that single-nucleotide polymorphisms associated with T2DM were negatively associated with ALS in the European sample, therefore suggesting that T2DM might be actually protective for ALS (OR $0.93,95 \%$ CI $0.88-0.99, p$ $=0.023$ ), rather than being the effect of potential confounders or reverse causality. An opposite despite no significant relationship was found in the Asian sample (OR 1.17, 95\% CI $0.93-1.47, p=0.190$ ). However, the authors stated that the smaller size of the Asian sample could account for the lack of significance [28].

\section{Pathogenic links}

The biological mechanisms linking DM to ALS remain unclear but it is likely that energy metabolism and homeostasis should be taken into account [5]. About 50\% of ALS patients show hypermetabolism (i.e., an increased energy expenditure) 
compared with controls and this could justify a higher consumption of glucose and lipids [47].

In a preclinical study setting, the correction of defects in energetics through a high-fat diet in mutant SOD1 mice delayed the ALS onset, improved the overall survival, and reduced muscle denervation [48]. A further study in mutant SOD1 mice reported that ALS progression could be mitigated by altering energy metabolism [29]. In particular, the altered energy metabolism reduced circulating leptin levels, an adipocyte-derived hormone that regulates the whole-animal energy expenditure, which in turn decreased the rate of weight loss, increased the white adipose tissue stores, decreased motor neuron degeneration, and finally improved survival. Furthermore, people affected by T2DM reported higher concentrations of progranulin [49], an adipokine that mediates high fat-induced insulin resistance and whose overexpression has been shown to revert mutant TDP-43-induced axonopathy in vivo [50].

In this optic, higher serum lipids or glucose could compensate ALS patients' hypermetabolism, thus reducing the rate of the damage caused by the hypermetabolic state on the motor neuron system [47] and delaying ALS onset [41].

TBK1 is considered among ALS minor genes and codes for the TANK-binding kinase 1[30]. In a genetic mouse model, TBK-1 has been proved to contribute to the phosphorylation of the insulin receptor, eventually attenuating its functionality. This evidence suggests that TBK1 could be involved in in vivo insulin resistance [51].

A recent review suggested the need to link together basic research with personalized medicine approaches to define new therapies based on cellular energetics in ALS [52]. However, alternative hypotheses should be also considered.

Uric acid has been suggested to predict survival in ALS and has also been positively associated with DM in high concentrations; thus, it could be considered as a potential pathogenic link between DM and ALS [11].

Glutamate excitotoxicity has been linked to motor neurons' death. Conversely, hyperglycemia has been suggested to increase glutamate uptake, thus protecting against excitotoxicity [11].

Vitamin A metabolism has been also studied. Indeed, high concentrations of serum retinol-binding protein 4 (RBP4), a specific transport protein of Vitamin A, resulted to be inversely correlated with the risk of ALS (OR 0.36, 95\% CI $0.22-$ 0.59 ). RBP4 has been investigated and has a proxy of insulin resistance [31]. Furthermore, retinoic acid, a metabolite of vitamin A playing an important role in the development and programmed cell death, was reported as relevant to the pathogenesis of ALS also in other studies [53].

A recent review focused on the role of insulin-like grow factor 1 (IGF-1) in both DM and ALS [54]. IGF-1 has a 50\% sequence homology with insulin and is able to elicit nearly the same hypoglycemic effects [55]. Several studies have reported an increased risk of insulin resistance and T2DM in subjects with low IGF-1 serum concentrations [56]. IGF-1 also promotes the survival of neurons and supports axon growth and has been shown to be lower in the cerebrospinal fluid of ALS patients when compared to controls $(p<0.0001)$ [57].

However, it should be highlighted that three randomized clinical trials (RCTs) have been conducted to test the disease-modifying effect of the recombinant human IGF-1 (rhIGF1) on ALS [58-60]. All these trials showed no clear beneficial effect of IGF-1 on ALS progression, whereas a meta-analysis concluded that, considering the two RCTs using the same outcome measure [58,60], a significant difference in favor of rhIGF-1 treatment was shown; however, the quality of the evidence from the two trials was low [61]. These results make it less probable for IGF-1 to play a crucial role in ALS pathogenesis and to represent the pathogenic link with DM.

An interesting review showed that chronically prolonged endoplasmic-reticulum (ER) stress is a hallmark of many common neurodegenerative and metabolic diseases, such as ALS and DM [62]. Several studies showed that ER stress occurs in motor neurons of human ALS patients [32]. Alteration in the ER functionality could lead to the production of unfolded proteins (UP) and UP response has been suggested to participate in carbohydrate metabolism [33].

A recent study focused on immune-mediated mechanisms. Altered humoral immunity was found to stimulate a pathological voltage-dependent $\mathrm{Ca} 2+$ entry in ALS motor neurons, thereby damaging these cells through a $\mathrm{Ca} 2+$ toxicity. Based on the evidence that motor neurons and islet cells share some mechanisms such as Ca2+-dependent exocytosis and triggered cell death, the study showed that IgG from ALS patients was able to interact with rodent islet cells, causing an $\mathrm{Ca} 2+-$ mediated impairment of mitochondrial function, insulin secretion, and cell viability [34].

Interestingly, in a recent study, an impaired insulin secretion in the early phases of the disease and a nuclear depletion of TDP-43 in pancreatic beta-cells of ALS patients have been demonstrated. The loss of TDP-43 was prominent in beta-cells when compared to alpha-cells, thus suggesting a specific role of TDP-43 in insulin secretion. Furthermore, when knocking down the TARDBP gene in a cultured beta-cells line, insulin secretion was inhibited, possibly through the downregulation of $\mathrm{Ca} 2+$ channels. Notably, ALS patients enrolled in this study had normal basal insulin secretion levels but lower insulinogenic index (IGI), an index of early-phase insulin secretion [35].

TDP-43-positive cytoplasmic inclusions can be found in almost all ALS cases [1]. TDP-43 has been shown to influence fat accumulation and insulin sensitivity in both the liver and the skeletal muscle [16] and these results further suggest its extra-neurological role. 


\section{Implications for ALS treatment}

A recent editorial focused on the need for treatments for ALS and on identifying a clear biological mechanism explanation for the association between DM and ALS [36]. However, it should be first clarified whether anti-diabetes drugs rather than DM itself could play a role in ALS risk and progression. An observational study showed that a wide group of diabetes drugs was associated with a decreased risk of developing ALS, thus suggesting their possible "repurposing" [63]. Several experimental pieces of evidence for the use of diabetes drugs in ALS have been collected so far.

\section{Pioglitazone and metformin}

A protocol of an observational cohort study was published in order to investigate whether prescribed drugs for the treatment of T2DM, among others, could be associated with the risk or the progression of several neurodegenerative diseases, including ALS [64].

Based on the decreased levels of inflammatory mediators in transgenic mouse models and the anti-oxidant and antiinflammatory effects of pioglitazone, a phase II, double-blind, multicentre, placebo-controlled trial on this drug ( $45 \mathrm{mg} /$ day) in 219 ALS patients treated with riluzole was conducted. However, pioglitazone did not confer a benefit on survival (HR 1.21, 95\% CI 0.71-2.07) [65]. Similar findings resulted in another study on the transgenic ${ }^{G 93 A} S O D 1$ mice exposed to metformin, another anti-diabetic drug with potent anti-inflammatory, and anti-oxidative proprieties, which showed a dosedependent negative effect on the disease progression in female mice $(p=0.036)[37]$.

\section{AMPK activators}

The enzyme AMP-activated protein kinase (AMPK) is a master regulator of energy balance [66]. AMPK is a common target for anti-diabetic drugs (for example, metformin) and the abnormal activation of AMPK was found in some neurodegenerative diseases, such as Alzheimer's disease (AD), Parkinson's disease, Huntington's disease (HD), and ALS, possibly because of its role in the autophagy network [67]. In the ${ }^{\mathrm{G} 93 \mathrm{~A}}$ SOD1 mice, the activation of AMPK via the use of latrepirdine resulted in a delayed symptom onset and a significant increase in lifespan $(p<0.01)$ [38], while an increased AMPK activity seems to play a negative role in motor neuron survival in another animal model [68].

In another preclinical study using TDP-43 transgenic mice, the downregulation of the $\alpha 1$ subunit of AMPK played a relevant role in reducing TDP-43 mislocalization and the development (and progression) of ALS, suggesting AMPK- $\alpha 1$ as a potential drug target [69]. The aberrant activation of AMPK can drastically impact the normal distribution of the human antigen $\mathrm{R}$ (HuR, a major mRNA stabilizer), which may imbalance RNA metabolism and contribute to ALS pathogenesis [70].

AMPK activators are widely prescribed to DM patients and should be further investigated as potential therapeutic strategies.

\section{Dietary modifications}

A Japanese case-control study revealed that combined high intakes of carbohydrate (adjusted OR 2.14, 95\% CI 1.054.36; the highest versus the lowest tertile) and low intakes of total fat (adjusted OR $0.41,95 \%$ CI $0.21-0.80$; the highest tertile versus the lowest) may increase the risk of ALS, suggesting that high-fat diet could be instead protective [39]. According to this hypothesis, in a mouse model, the administration of a ketogenic diet led to an improvement of motor neuron survival and motor function [71]. Furthermore, a human study demonstrated that among patients treated with high caloric enteral diet, those who received high carbohydrate had a smaller total number of adverse events ( 0 versus 9$)$ and death ( $0 \%$ versus $43 \%$ ) than those received high fat or control group [40], in keeping with the hypothesized protective role of hyperlipidemia on ALS survival [27].

\section{The sirtuins pathway}

Mammalian sirtuins are a group of seven NAD+-dependent enzymes able to deacetylate many intracellular proteins involved in many processes, including carbohydrate and lipid metabolism, apoptosis, and autophagy [72]. Accordingly, sirtuins were suggested to be protective against $\mathrm{AD}, \mathrm{HD}$, and ALS, via several mechanisms like regulation of stress response, apoptosis, and DNA repair [71, 73]. Moreover, SIRT2 was found to be inversely associated with mitochondrial fragmentation and neuronal cell death in ${ }^{\mathrm{G} 93 \mathrm{~A}} \mathrm{SOD} 1$ transgenic mice [74]. Sirtuin activators have been proposed as a therapeutic target in DM and could be considered as a potentially valuable therapeutic factor in ALS [73].

\section{Discussion}

Recent literature converged into stating that DM diagnosed at younger ages has a detrimental or null effect on the development of ALS; when DM is diagnosed at older ages (about 50 60 years), as it happens more commonly, it shows a protective effect on the ALS risk. There is no clear explanation for this age effect and some studies did not confirm it [15].

A possible explanation is that this age cutoff excludes most T1DM cases that rely on different pathogenic mechanisms [8]. However, such a phenomenon should be further studied since 
the distinction between T1DM and T2DM solely on basis of age could be imprecise [3].

Also, competing DM and ALS risks at older ages should be taken into account as a possible explanation.

The protective role of DM on ALS was not confirmed in the East Asian population where T2DM seems to increase the risk of ALS $[12,28]$. It is plausible to think that genetic and environmental factors could act differently across populations, thus varying the terms of this interaction [16]. However, only two studies provided such opposite results and further pieces of evidence should be sought.

It remains unclear whether T2DM and ALS are linked by a causal relationship. Indeed, because of the retrospective observational nature of all these studies, despite most of them have attempted to adjust for some known confounding factors, it is impossible to completely rule out known not considered and unknown potential confounders. Conversely, the low frequency of ALS and obvious ethical aspects hamper observational prospective and experimental studies. Mendelian randomization (MR) could give useful hints in the attempt of moving beyond these limits and the study by Zeng et al. could be considered as proof of the causal relationship of diabetes on ALS [28]. However, MR is not without intrinsic limitations and it cannot entirely rule out the role of possible confounders and reverse causation $[28,75]$. Therefore, it remains still unclear if T2DM could be considered as protective to ALS, if ALS causes the lack of T2DM (together with other metabolic conditions) or if both are caused, with opposite relationships, by a third not considered confounding factor.

In the light of a possible repurposing of drugs acting on glucose metabolism, clarifying the relationship between DM and ALS becomes crucial. Some preclinical studies showed positive results so far $[31,38,70]$. However, in a sensitivity analysis, Zeng et al. showed that fasting glucose, fasting insulin, and $\mathrm{Hb} 1 \mathrm{Ac}$ do not share a causal relationship with ALS [28]. Thus, intervening on such factors could be ineffective and other targets, maybe occurring upstream in the pathogenic pathways, should be investigated. Together with the heterogeneity of ALS, this observation could justify the negative results of some trials using anti-diabetic drugs for modifying the risk of ALS. Furthermore, the possible opposite effect of DM on ALS in Europe and Asia could impose different therapeutic strategies in these two populations.

Interestingly, despite suggested as a protective factor, several studies showed that T2DM does not affect ALS prognosis. Such discrepancy could be interpreted as a lack of causal relationship between DM and ALS. However, it is not possible to exclude that ALS pathogenesis involves several pathways at different times, each one showing variable vulnerability to DM.

DM is usually part of a wider modification of metabolism known as metabolic syndrome [76]. Thus, focusing on the relationship of ALS with DM could mean missing the big picture. The most widely accepted hypothesis considers insulin resistance as the pathogenic center of metabolic syndrome [76]. Insulin inhibits lipase thus allowing the delivery of free fatty acids (FFAs) from the adipose tissue. In turn, FFAs inhibit, by a negative feedback mechanism, the action of insulin. This justifies how insulin resistance could lead to the accumulation of adipose tissue thus leading to obesity and how, on the contrary, obesity could result in insulin resistance [76]. Accordingly, obesity showed a similar effect to DM in ALS risk. With some exception in American studies [77], results converged into the hypothesis that elevated pre-diagnostic and baseline BMI scores are protective against both onset and survival of ALS and that conversely lower BMI is detrimental in developing the disease $[7,78]$. A recent study showed that patients' survival was related to the mean monthly percentage of weight loss at diagnosis $(p<0.0001)$ but not to pre-morbid BMI or BMI at diagnosis [79]. However, one study considered both obesity and DM and showed that DM was an independent prognostic factor on ALS risk [11].

In the setting of insulin resistance, the increased flux of FFAs to the liver results in increased triglyceride synthesis. This could justify the frequent co-occurrence of DM with the overproduction of very-low-density lipoproteins (VLDL), hypertriglyceridemia, and the reduction of HDL cholesterol [76]. Dyslipidemia together with a low-level inflammatory state that seems to even precede the appearance of insulin resistance [80] leads to vascular damage, arterial hypertension, and ultimately to a higher risk of cardiovascular diseases (CVDs) [76].

According to the inverse association of DM and ALS risk, hypercholesterolemia has been found less frequently among ALS patients than controls [14] and has been reported to be inversely associated with ALS onset [7]. Moreover, hyperlipidemia seems to delay the age of ALS onset and prolong life expectancy [27]. Further pieces of evidence showed lower frequencies of arterial hypertension, cardiac arrhythmia, and myocardial infarction among ALS patients [19].

However, results are inconsistent across literature and other studies reported no altered lipid levels in ALS patients [81]. A previous study showed no significant influence of hypertension, cardiac arrhythmia, and coronary heart disease on ALS survival [19] while two recent studies showed that the comorbidity of hypertension and heart disease was associated with reduced survival in ALS [23, 24]. Finally, it has been suggested that BMI rather than hyperlipidemia could influence ALS prognosis [78, 82].

Despite such metabolic abnormalities that could be read as epiphenomena of insulin resistance, a recent MR study demonstrated that dyslipidemia could be causative itself [83].

As a final remark, it remains unclear whether all metabolic findings could be a compensation for hypermetabolism found in ALS patients [5]. Despite hyperglycemia, early weight loss, and dyslipidemia could be read as compensation effect of a 
high energy expenditure, in the absence of studies on presymptomatic patients, it remains unclear if hypermetabolism is a product or a cause of the neurodegenerative process [84].

In conclusion, DM and ALS seem to be inversely correlated as concerning ALS risk; conversely, the findings on the effect of DM on ALS prognosis are inconclusive. The exact causal relationship between DM and ALS remains unclear. However, such a relationship should be read as the piece of a larger metabolic dysfunction and could be related to the finding of hypermetabolism in ALS patients. Further genetics studies using techniques such as MR could be helpful in disentangling this complex metabolic, possibly across different ethnic backgrounds.

Funding Open Access funding provided by Università degli Studi di Torino.

Data availability Data sharing is not applicable to this article as no new data were created or analyzed in the study.

\section{Declarations}

\section{Ethical approval Not required.}

Conflict of interest Rosario Vasta, Fabrizio d'Ovidio: no disclosures. Giancarlo Logroscino is associated editor of the Neuroepidemiology journal (Karger, Basel). He has received support from: (1) Regione Puglia (DGR n. 1284 - 27.05.2015) for the project "Registro Regionale per la SLA, la FTD-P e le patologie affini in Regione Puglia (SLAPDem register- www.slapdem.it) and from Italian Ministry of Health (Ricerca Corrente); (2) Regione Puglia and Consiglio Nazionale delle Ricerche (CNR) for Tecnomed Puglia for Precision Medicine D.G.R. n. 2117 of 21.11.2018. Adriano Chiò serves on the editorial advisory board of Amyotrophic Lateral Sclerosis and Neurological Sciences and has received research support from the Italian Ministry of Health (Ricerca Finalizzata), Regione Piemonte (Ricerca Finalizzata), University of Turin, and the European Commission (Health Seventh Framework Programme), and serves on scientific advisory boards for Biogen Idec, Cytokinetics, and Avexis.

\section{Informed consent Not applicable.}

Open Access This article is licensed under a Creative Commons Attribution 4.0 International License, which permits use, sharing, adaptation, distribution and reproduction in any medium or format, as long as you give appropriate credit to the original author(s) and the source, provide a link to the Creative Commons licence, and indicate if changes were made. The images or other third party material in this article are included in the article's Creative Commons licence, unless indicated otherwise in a credit line to the material. If material is not included in the article's Creative Commons licence and your intended use is not permitted by statutory regulation or exceeds the permitted use, you will need to obtain permission directly from the copyright holder. To view a copy of this licence, visit http://creativecommons.org/licenses/by/4.0/.

\section{References}

1. Kiernan MC, Vucic S, Cheah BC, Turner MR, Eisen A, Hardiman O, Burrell JR, Zoing MC (2011) Amyotrophic lateral sclerosis.
Lancet Lond Engl 377:942-955. https://doi.org/10.1016/S01406736(10)61156-7

2. Ingre $\mathrm{C}$, Roos PM, Piehl $\mathrm{F}$ et al (2015) Risk factors for amyotrophic lateral sclerosis. Clin Epidemiol 7:181-193. https://doi.org/10. 2147/CLEP.S37505

3. (2013) Diagnosis and classification of diabetes mellitus. Diabetes Care 36:S67-S74. https://doi.org/10.2337/dc13-S067

4. WHO | Global report on diabetes. In: WHO. http://www.who.int/ diabetes/publications/grd-2016/en/. Accessed 16 Jan 2020

5. Dupuis L, Pradat P-F, Ludolph AC, Loeffler J-P (2011) Energy metabolism in amyotrophic lateral sclerosis. Lancet Neurol 10: 75-82. https://doi.org/10.1016/S1474-4422(10)70224-6

6. Brito MD, da Silva GFG, Tilieri EM, Araujo BG, Calió ML, Rosenstock TR (2019) Metabolic alteration and amyotrophic lateral sclerosis outcome: a systematic review. Front Neurol 10:1205. https://doi.org/10.3389/fneur.2019.01205

7. Mitchell CS, Hollinger SK, Goswami SD, Polak MA, Lee RH, Glass JD (2015) Antecedent disease is less prevalent in amyotrophic lateral sclerosis. Neurodegener Dis 15:109-113. https://doi. org/10.1159/000369812

8. Mariosa D, Kamel F, Bellocco R, Ye W, Fang F (2015) Association between diabetes and amyotrophic lateral sclerosis in Sweden. Eur J Neurol 22:1436-1442. https://doi.org/10.1111/ene.12632

9. Kawada T (2016) Type 2 diabetes and amyotrophic lateral sclerosis. Eur J Neurol 23:e9. https://doi.org/10.1111/ene.12893

10. Mariosa D, Fang F (2016) Response to the letter "Type 2 diabetes and amyotrophic lateral sclerosis.”. Eur J Neurol 23:e26. https://doi. org/10.1111/ene. 12928

11. Kioumourtzoglou M-A, Rotem RS, Seals RM, Gredal O, Hansen J, Weisskopf MG (2015) Diabetes mellitus, obesity, and diagnosis of amyotrophic lateral sclerosis: a population-based study. JAMA Neurol 72:905-911. https://doi.org/10.1001/jamaneurol.2015.0910

12. Sun Y, Lu C-J, Chen R-C, Hou WH, Li CY (2015) Risk of amyotrophic lateral sclerosis in patients with diabetes: a nationwide population-based cohort study. J Epidemiol 25:445-451. https:// doi.org/10.2188/jea.JE20140176

13. Tsai C-P, Lee JK-W, Lee CT-C (2019) Type II diabetes mellitus and the incidence of amyotrophic lateral sclerosis. J Neurol 266: 2233-2243. https://doi.org/10.1007/s00415-019-09405-x

14. Seelen M, van Doormaal PTC, Visser AE, Huisman MHB, Roozekrans MHJ, de Jong SW, van der Kooi AJ, de Visser M, Voermans NC, Veldink JH, van den Berg LH (2014) Prior medical conditions and the risk of amyotrophic lateral sclerosis. J Neurol 261:1949-1956. https://doi.org/10.1007/s00415-014-7445-1

15. D'Ovidio F, d'Errico A, Carnà $P$ et al (2018) The role of pre-morbid diabetes on developing amyotrophic lateral sclerosis. Eur J Neurol 25:164-170. https://doi.org/10.1111/ene.13465

16. Logroscino G (2015) Motor neuron disease: are diabetes and amyotrophic lateral sclerosis related? Nat Rev Neurol 11:488-490. https://doi.org/10.1038/nrneurol.2015.145

17. Turner MR, Goldacre R, Ramagopalan S, Talbot K, Goldacre MJ (2013) Autoimmune disease preceding amyotrophic lateral sclerosis: an epidemiologic study. Neurology 81:1222-1225. https://doi. org/10.1212/WNL.0b013e3182a6cc13

18. Jawaid A, Brown JA, Schulz PE (2015) Diabetes mellitus in amyotrophic lateral sclerosis: Dr. Jekyll or Mr. Hyde? Eur J Neurol 22: 1419-1420. https://doi.org/10.1111/ene.12660

19. Körner S, Kollewe K, Ilsemann J, Müller-Heine A, Dengler R, Krampfl K, Petri S (2013) Prevalence and prognostic impact of comorbidities in amyotrophic lateral sclerosis. Eur J Neurol 20: 647-654. https://doi.org/10.1111/ene.12015

20. Paganoni S, Hyman T, Shui A, Allred P, Harms M, Liu J, Maragakis N, Schoenfeld D, Yu H, Atassi N, Cudkowicz M, Miller TM (2015) Pre-morbid type 2 diabetes mellitus is not a prognostic factor in amyotrophic lateral sclerosis. Muscle Nerve 52:339-343. https://doi.org/10.1002/mus.24688 
21. Jawaid A, Schulz PE (2015) Pre-morbid type 2 diabetes mellitus as a prognostic factor in amyotrophic lateral sclerosis. Muscle Nerve 52:690-691. https://doi.org/10.1002/mus.24758

22. Paganoni S, Schoenfeld D, Shui A, Cudkowicz M, Miller TM (2015) Reply: To. Muscle Nerve 52:691. https://doi.org/10.1002/ mus. 24760

23. Mandrioli J, Ferri L, Fasano A, Zucchi E, Fini N, Moglia C, Lunetta C, Marinou K, Ticozzi N, Drago Ferrante G, Scialo C, Sorarù G, Trojsi F, Conte A, Falzone YM, Tortelli R, Russo M, Sansone VA, Mora G, Silani V, Volanti P, Caponnetto C, Querin G, Monsurrò MR, Sabatelli M, Chiò A, Riva N, Logroscino G, Messina S, Calvo A (2018) Cardiovascular diseases may play a negative role in the prognosis of amyotrophic lateral sclerosis. Eur J Neurol 25:861868. https://doi.org/10.1111/ene. 13620

24. Moglia C, Calvo A, Canosa A, Bertuzzo D, Cugnasco P, Solero L, Grassano M, Bersano E, Cammarosano S, Manera U, Parals, Pisano F, Mazzini L, Dalla Vecchia LA, Mora G, Chiò A (2017) Influence of arterial hypertension, type 2 diabetes and cardiovascular risk factors on ALS outcome: a population-based study. Amyotroph Lateral Scler Front Degener 18:590-597. https://doi.org/10.1080/ 21678421.2017.1336560

25. Wei Q-Q, Chen Y, Cao B, Ou RW, Zhang L, Hou Y, Gao X, Shang H (2017) Blood hemoglobin A1c levels and amyotrophic lateral sclerosis survival. Mol Neurodegener 12:69. https://doi.org/10. 1186/s13024-017-0211-y

26. Zhang L, Chen L, Fan D (2019) The protective role of pre-morbid type 2 diabetes in patients with amyotrophic lateral sclerosis: a center-based survey in China. Amyotroph Lateral Scler Front Degener:1-7. https://doi.org/10.1080/21678421.2019.1704010

27. Hollinger SK, Okosun IS, Mitchell CS (2016) Antecedent disease and amyotrophic lateral sclerosis: what is protecting whom? Front Neurol 7:47. https://doi.org/10.3389/fneur.2016.00047

28. Zeng P, Wang T, Zheng J, Zhou X (2019) Causal association of type 2 diabetes with amyotrophic lateral sclerosis: new evidence from Mendelian randomization using GWAS summary statistics. BMC Med 17:225. https://doi.org/10.1186/s12916-019-1448-9

29. Lim MA, Bence KK, Sandesara I, Andreux P, Auwerx J, Ishibashi J, Seale P, Kalb RG (2014) Genetically altering organismal metabolism by leptin-deficiency benefits a mouse model of amyotrophic lateral sclerosis. Hum Mol Genet 23:4995-5008. https://doi.org/10. 1093/hmg/ddu214

30. Borghero G, Pugliatti M, Marrosu F et al (2016) TBK1 is associated with ALS and ALS-FTD in Sardinian patients. Neurobiol Aging 43:180.e1-180.e5. https://doi.org/10.1016/j.neurobiolaging.2016. 03.028

31. Rosenbohm A, Nagel G, Peter RS, Brehme T, Koenig W, Dupuis L, Rothenbacher D, Ludolph AC, for the ALS Registry Study Group (2018) Association of serum retinol-binding protein 4 concentration with risk for and prognosis of amyotrophic lateral sclerosis. JAMA Neurol 75:600-607. https://doi.org/10.1001/ jamaneurol.2017.5129

32. Jaronen M, Goldsteins G, Koistinaho J (2014) ER stress and unfolded protein response in amyotrophic lateral sclerosis-a controversial role of protein disulphide isomerase. Front Cell Neurosci 8: 402. https://doi.org/10.3389/fncel.2014.00402

33. Kanekura K, Suzuki H, Aiso S, Matsuoka M (2009) ER stress and unfolded protein response in amyotrophic lateral sclerosis. Mol Neurobiol 39:81-89. https://doi.org/10.1007/s12035-009-8054-3

34. Shi Y, Park KS, Kim SH, Yu J, Zhao K, Yu L, Oh KW, Lee K, Kim J, Chaggar K, Li Y, Dolphin AC, Catterall WA, Ryu SH, Yang SN, Berggren PO (2019) IgGs from patients with amyotrophic lateral sclerosis and diabetes target $\mathrm{CaV} \alpha 2 \delta 1$ subunits impairing islet cell function and survival. Proc Natl Acad Sci U S A 116:26816-26822. https://doi.org/10.1073/pnas.1911956116

35. Araki K, Araki A, Honda D, Izumoto T, Hashizume A, Hijikata Y, Yamada S, Iguchi Y, Hara A, Ikumi K, Kawai K, Ishigaki S,
Nakamichi Y, Tsunekawa S, Seino Y, Yamamoto A, Takayama Y, Hidaka S, Tominaga M, Ohara-Imaizumi M, Suzuki A, Ishiguro H, Enomoto A, Yoshida M, Arima H, Muramatsu SI, Sobue G, Katsuno M (2019) TDP-43 regulates early-phase insulin secretion via CaV1.2-mediated exocytosis in islets. J Clin Invest 130:3578-3593. https://doi.org/10.1172/JCI124481

36. Jawaid A, Abid A, Schulz PE (2018) Diabetes mellitus and amyotrophic lateral sclerosis: time to bridge the gap between the bench and the bedside. Eur J Neurol 25:3-4. https://doi.org/10.1111/ene. 13481

37. Kaneb HM, Sharp PS, Rahmani-Kondori N, Wells DJ (2011) Metformin treatment has no beneficial effect in a dose-response survival study in the SOD1(G93A) mouse model of ALS and is harmful in female mice. PLoS One 6:e24189. https://doi.org/10. 1371/journal.pone.0024189

38. Coughlan KS, Mitchem MR, Hogg MC, Prehn JHM (2015) "Preconditioning" with latrepirdine, an adenosine 5'monophosphate-activated protein kinase activator, delays amyotrophic lateral sclerosis progression in SOD1(G93A) mice. Neurobiol Aging 36:1140-1150. https://doi.org/10.1016/j.neurobiolaging. 2014.09.022

39. Okamoto K, Kihira T, Kondo T, Kobashi G, Washio M, Sasaki S, Yokoyama T, Miyake Y, Sakamoto N, Inaba Y, Nagai M (2007) Nutritional status and risk of amyotrophic lateral sclerosis in Japan. Amyotroph Lateral Scler Off Publ World Fed Neurol Res Group Mot Neuron Dis 8:300-304. https://doi.org/10.1080/ 17482960701472249

40. Wills A-M, Hubbard J, Macklin EA, Glass J, Tandan R, Simpson EP, Brooks B, Gelinas D, Mitsumoto H, Mozaffar T, Hanes GP, Ladha SS, Heiman-Patterson T, Katz J, Lou JS, Mahoney K, Grasso D, Lawson R, Yu H, Cudkowicz M, MDA Clinical Research Network (2014) Hypercaloric enteral nutrition in patients with amyotrophic lateral sclerosis: a randomised, double-blind, placebo-controlled phase 2 trial. Lancet Lond Engl 383:20652072. https://doi.org/10.1016/S0140-6736(14)60222-1

41. Jawaid A, Salamone AR, Strutt AM, Murthy SB, Wheaton M, McDowell EJ, Simpson E, Appel SH, York MK, Schulz PE (2010) ALS disease onset may occur later in patients with premorbid diabetes mellitus. Eur J Neurol 17:733-739. https://doi. org/10.1111/j.1468-1331.2009.02923.x

42. Ali O (2013) Genetics of type 2 diabetes. World J Diabetes 4:114 123. https://doi.org/10.4239/wjd.v4.i4.114

43. Chia R, Chiò A, Traynor BJ (2018) Novel genes associated with amyotrophic lateral sclerosis: diagnostic and clinical implications. Lancet Neurol 17:94-102. https://doi.org/10.1016/S1474-4422(17) 30401-5

44. Auburger G, Gispert S, Lahut S, Omür O, Damrath E, Heck M, Başak N (2014) 12q24 locus association with type 1 diabetes: SH2B3 or ATXN2? World J Diabetes 5:316-327. https://doi.org/ 10.4239/wjd.v5.i3.316

45. Elden AC, Kim H-J, Hart MP, Chen-Plotkin AS, Johnson BS, Fang X, Armakola M, Geser F, Greene R, Lu MM, Padmanabhan A, Clay-Falcone D, McCluskey L, Elman L, Juhr D, Gruber PJ, Rüb U, Auburger G, Trojanowski JQ, Lee VMY, van Deerlin VM, Bonini NM, Gitler AD (2010) Ataxin-2 intermediate-length polyglutamine expansions are associated with increased risk for ALS. Nature 466:1069-1075. https://doi.org/10.1038/nature09320

46. Lahut S, Ömür Ö, Uyan Ö, Ağım ZS, Özoğuz A, Parman Y, Deymeer F, Oflazer P, Koç F, Özçelik H, Auburger G, Başak AN (2012) ATXN2 and its neighbouring gene SH2B3 are associated with increased ALS risk in the Turkish population. PLoS One 7: e42956. https://doi.org/10.1371/journal.pone.0042956

47. Bouteloup C, Desport J-C, Clavelou P, Guy N, Derumeaux-Burel H, Ferrier A, Couratier P (2009) Hypermetabolism in ALS patients: an early and persistent phenomenon. J Neurol 256:1236-1242. https://doi.org/10.1007/s00415-009-5100-z 
48. Dupuis L, Oudart H, René F et al (2004) Evidence for defective energy homeostasis in amyotrophic lateral sclerosis: benefit of a high-energy diet in a transgenic mouse model. Proc Natl Acad Sci U S A 101:11159-11164. https://doi.org/10.1073/pnas. 0402026101

49. Qu H, Deng H, Hu Z (2013) Plasma progranulin concentrations are increased in patients with type 2 diabetes and obesity and correlated with insulin resistance. Mediat Inflamm 2013:360190-360196. https://doi.org/10.1155/2013/360190

50. Laird AS, Van Hoecke A, De Muynck L et al (2010) Progranulin is neurotrophic in vivo and protects against a mutant TDP-43 induced axonopathy. PLoS One 5:e13368. https://doi.org/10.1371/journal. pone. 0013368

51. Muñoz MC, Giani JF, Mayer MA, Toblli JE, Turyn D, Dominici FP (2009) TANK-binding kinase 1 mediates phosphorylation of insulin receptor at serine residue 994: a potential link between inflammation and insulin resistance. J Endocrinol 201:185-197. https:// doi.org/10.1677/JOE-08-0276

52. Joardar A, Manzo E, Zarnescu DC (2017) Metabolic dysregulation in amyotrophic lateral sclerosis: challenges and opportunities. Curr Genet Med Rep 5:108-114. https://doi.org/10.1007/s40142-0170123-8

53. Riancho J, Berciano MT, Ruiz-Soto M, Berciano J, Landreth G, Lafarga M (2016) Retinoids and motor neuron disease: potential role in amyotrophic lateral sclerosis. J Neurol Sci 360:115-120. https://doi.org/10.1016/j.jns.2015.11.058

54. Rauskolb S, Dombert B, Sendtner M (2017) Insulin-like growth factor 1 in diabetic neuropathy and amyotrophic lateral sclerosis. Neurobiol Dis 97:103-113. https://doi.org/10.1016/j.nbd.2016.04. 007

55. Boulware SD, Tamborlane WV, Rennert NJ, Gesundheit N, Sherwin RS (1994) Comparison of the metabolic effects of recombinant human insulin-like growth factor-I and insulin. Doseresponse relationships in healthy young and middle-aged adults. $\mathrm{J}$ Clin Invest 93:1131-1139. https://doi.org/10.1172/JCI117065

56. Friedrich N, Thuesen B, Jørgensen $\mathrm{T}$ et al (2012) The association between IGF-I and insulin resistance: a general population study in Danish adults. Diabetes Care 35:768-773. https://doi.org/10.2337/ dc11-1833

57. Bilic E, Bilic E, Rudan I, Kusec V, Zurak N, Delimar D, Zagar M (2006) Comparison of the growth hormone, IGF-1 and insulin in cerebrospinal fluid and serum between patients with motor neuron disease and healthy controls. Eur J Neurol 13:1340-1345. https:// doi.org/10.1111/j.1468-1331.2006.01503.x

58. Lai EC, Felice KJ, Festoff BW, Gawel MJ, Gelinas DF, Kratz R, Murphy MF, Natter HM, Norris FH, Rudnicki SA, The North America ALS/IGF-I Study Group* (1997) Effect of recombinant human insulin-like growth factor-I on progression of ALS. A placebo-controlled study. The North America ALS/IGF-I Study Group. Neurology 49:1621-1630. https://doi.org/10.1212/wnl.49. 6.1621

59. Sorenson EJ, Windbank AJ, Mandrekar JN, Bamlet WR, Appel SH, Armon C, Barkhaus PE, Bosch P, Boylan K, David WS, Feldman E, Glass J, Gutmann L, Katz J, King W, Luciano CA, McCluskey LF, Nash S, Newman DS, Pascuzzi RM, Pioro E, Sams LJ, Scelsa S, Simpson EP, Subramony SH, Tiryaki E, Thornton CA (2008) Subcutaneous IGF-1 is not beneficial in 2year ALS trial. Neurology 71:1770-1775. https://doi.org/10.1212/ 01.wnl.0000335970.78664.36

60. Borasio GD, Robberecht W, Leigh PN, Emile J, Guiloff RJ, Jerusalem F, Silani V, Vos PE, Wokke JHJ, Dobbins T, European ALS/IGF-I Study Group* (1998) A placebo-controlled trial of insulin-like growth factor-I in amyotrophic lateral sclerosis. European ALS/IGF-I Study Group. Neurology 51:583-586. https://doi.org/10.1212/wnl.51.2.583
61. Beauverd M, Mitchell JD, Wokke JHJ, Borasio GD (2012) Recombinant human insulin-like growth factor I (rhIGF-I) for the treatment of amyotrophic lateral sclerosis/motor neuron disease. Cochrane Database Syst Rev 11:CD002064. https://doi.org/10. 1002/14651858.CD002064.pub3

62. Sano R, Reed JC (2013) ER stress-induced cell death mechanisms. Biochim Biophys Acta 1833:3460-3470. https://doi.org/10.1016/j. bbamcr.2013.06.028

63. Pfeiffer RM, Mayer B, Kuncl RW et al (2019) Identifying potential targets for prevention and treatment of amyotrophic lateral sclerosis based on a screen of Medicare prescription drugs. Amyotroph Lateral Scler Front Degener:1-11. https://doi.org/10.1080/ 21678421.2019.1682613

64. Walker VM, Davies NM, Jones T, Kehoe PG, Martin RM (2016) Can commonly prescribed drugs be repurposed for the prevention or treatment of Alzheimer's and other neurodegenerative diseases? Protocol for an observational cohort study in the UK Clinical Practice Research Datalink. BMJ Open 6:e012044. https://doi.org/ 10.1136/bmjopen-2016-012044

65. Dupuis L, Dengler R, Heneka MT, Meyer T, Zierz S, Kassubek J, Fischer W, Steiner F, Lindauer E, Otto M, Dreyhaupt J, Grehl T, Hermann A, Winkler AS, Bogdahn U, Benecke R, Schrank B, Wessig C, Grosskreutz J, Ludolph AC, the GERP ALS Study Group (2012) A randomized, double blind, placebo-controlled trial of pioglitazone in combination with riluzole in amyotrophic lateral sclerosis. PLoS One 7:e37885. https://doi.org/10.1371/journal. pone. 0037885

66. Herzig S, Shaw RJ (2018) AMPK: guardian of metabolism and mitochondrial homeostasis. Nat Rev Mol Cell Biol 19:121-135. https://doi.org/10.1038/nrm.2017.95

67. Liu Y-J, Chern Y (2015) AMPK-mediated regulation of neuronal metabolism and function in brain diseases. J Neurogenet 29:50-58. https://doi.org/10.3109/01677063.2015.1067203

68. Zhao Z, Sui Y, Gao W, Cai B, Fan D (2015) Effects of diet on adenosine monophosphate-activated protein kinase activity and disease progression in an amyotrophic lateral sclerosis model. J Int Med Res 43:67-79. https://doi.org/10.1177/0300060514554725

69. Liu Y-J, Ju T-C, Chen H-M, Jang YS, Lee LM, Lai HL, Tai HC, Fang JM, Lin YL, Tu PH, Chern Y (2015) Activation of AMPactivated protein kinase $\alpha 1$ mediates mislocalization of TDP-43 in amyotrophic lateral sclerosis. Amyotroph Lateral Scler Front Degener 24:787-801. https://doi.org/10.1093/hmg/ddu497

70. Liu Y-J, Lee L-M, Lai H-L, Chern Y (2015) Aberrant activation of AMP-activated protein kinase contributes to the abnormal distribution of HuR in amyotrophic lateral sclerosis. FEBS Lett 589:432 439. https://doi.org/10.1016/j.febslet.2014.12.029

71. Zhao Z, Lange DJ, Voustianiouk A, MacGrogan D, Ho L, Suh J, Humala N, Thiyagarajan M, Wang J, Pasinetti GM (2006) A ketogenic diet as a potential novel therapeutic intervention in amyotrophic lateral sclerosis. BMC Neurosci 7:29. https://doi.org/10.1186/ 1471-2202-7-29

72. Pasinetti GM, Bilski AE, Zhao W (2013) Sirtuins as therapeutic targets of ALS. Cell Res 23:1073-1074. https://doi.org/10.1038/ cr.2013.94

73. Herskovits AZ, Guarente L (2013) Sirtuin deacetylases in neurodegenerative diseases of aging. Cell Res 23:746-758. https://doi.org/ 10.1038/cr.2013.70

74. Song W, Song Y, Kincaid B, Bossy B, Bossy-Wetzel E (2013) Mutant SOD1G93A triggers mitochondrial fragmentation in spinal cord motor neurons: neuroprotection by SIRT3 and PGC- $1 \alpha$. Neurobiol Dis 51:72-81. https://doi.org/10.1016/j.nbd.2012.07. 004

75. Bandres-Ciga S, Noyce AJ, Traynor BJ (2019) Mendelian randomization-a journey from obscurity to center stage with a few potholes along the way. JAMA Neurol 77:7-8. https://doi. org/10.1001/jamaneurol.2019.3419 
76. Eckel RH, Alberti KGMM, Grundy SM, Zimmet PZ (2010) The metabolic syndrome. Lancet Lond Engl 375:181-183. https://doi. org/10.1016/S0140-6736(09)61794-3

77. Gray N, Picone G, Sloan F, Yashkin A (2015) The relationship between BMI and onset of diabetes mellitus and its complications. South Med J 108:29-36. https://doi.org/10.14423/SMJ. 0000000000000214

78. Paganoni S, Deng J, Jaffa M, Cudkowicz ME, Wills AM (2011) Body mass index, not dyslipidemia, is an independent predictor of survival in amyotrophic lateral sclerosis. Muscle Nerve 44:20-24. https://doi.org/10.1002/mus.22114

79. Moglia C, Calvo A, Grassano M, Canosa A, Manera U, D'Ovidio F, Bombaci A, Bersano E, Mazzini L, Mora G, Chiò A (2019) Early weight loss in amyotrophic lateral sclerosis: outcome relevance and clinical correlates in a population-based cohort. J Neurol Neurosurg Psychiatry 90:666-673. https://doi.org/10.1136/jnnp-2018-319611

80. Dokken BB (2008) The pathophysiology of cardiovascular disease and diabetes: beyond blood pressure and lipids. Diabetes Spectr 21: 160-165. https://doi.org/10.2337/diaspect.21.3.160

81. Chiò A, Calvo A, Ilardi A et al (2009) Lower serum lipid levels are related to respiratory impairment in patients with ALS. Neurology 73:1681-1685. https://doi.org/10.1212/WNL.0b013e3181c1dfle

82. Calvo A, Moglia C, Lunetta C, Marinou K, Ticozzi N, Ferrante GD, Scialo C, Sorarù G, Trojsi F, Conte A, Falzone YM, Tortelli R, Russo M, Chiò A, Sansone VA, Mora G, Silani V, Volanti P, Caponnetto C, Querin G, Monsurrò MR, Sabatelli M, Riva N, Logroscino G, Messina S, Fini N, Mandrioli J (2017) Factors predicting survival in ALS: a multicenter Italian study. J Neurol 264:54-63. https://doi.org/10.1007/s00415-016-8313-y

83. Bandres-Ciga S, Noyce AJ, Hemani G, Nicolas A, Calvo A, Mora G, The ITALSGEN Consortium, Arosio A, Barberis M, Bartolomei I, Battistini S, Benigni M, Borghero G, Brunetti M, Calvo A, Cammarosano S, Cannas A, Canosa A, Capasso M, Caponnetto C, Caredda C, Carrera P, Casale F, Cavallaro S, Chiò A, Colletti T, Conforti FL, Conte A, Corrado L, Costantino E, D'Alfonso S, Fasano A, Femiano C, Ferrarese C, Fini N, Floris G, Fuda G,
Giannini F, Grassano M, Ilardi A, la Bella V, Lattante S, Logroscino G, Logullo FO, Loi D, Lunetta C, Mancardi G, Mandich P, Mandrioli J, Manera U, Marangi G, Marinou K, Marrali G, Marrosu MG, Mazzini L, Melis M, Messina S, Moglia C, Monsurro MR, Mora G, Mosca L, Occhineri P, Origone P, Pani C, Penco S, Petrucci A, Piccirillo G, Pirisi A, Pisano F, Pugliatti M, Restagno G, Ricci C, Rita Murru M, Riva N, Sabatelli M, Salvi F, Santarelli M, Sideri R, Simone I, Spataro R, Tanel R, Tedeschi G, Tranquilli S, Tremolizzo L, Trojsi F, Volanti P, Zollino M, The International ALS Genomics Consortium, Abramzon Y, Arepalli S, Baloh RH, Bowser R, Brady CB, Brice A, Broach J, Campbell RH, Camu W, Chia R, Chiò A, Cooper-Knock J, Cusi D, Ding J, Drepper C, Drory VE, Dunckley TL, Eicher JD, Faghri F, Feldman E, Kay Floeter M, Fratta P, Geiger JT, Gerhard G, Gibbs JR, Gibson SB, Glass JD, Hardy J, Harms MB, Heiman-Patterson TD, Hernandez DG, Jansson L, Kamel F, Kirby J, Kowall NW, Laaksovirta H, Landi F, le Ber I, Lumbroso S, MacGowan DJL, Maragakis NJ, Mouzat K, Murphy NA, Myllykangas L, Nalls MA, Nicolas A, Orrell RW, Ostrow LW, Pamphlett R, Pickering-Brown S, Pioro E, Pliner HA, Pulst SM, Ravits JM, Renton AE, Rivera A, Robbrecht W, Rogaeva E, Rollinson S, Rothstein JD, Salvi E, Scholz SW, Sendtner M, Shaw PJ, Sidle KC, Simmons Z, Singleton AB, Stone DC, Sulkava R, Tienari PJ, Traynor BJ, Trojanowski JQ, Troncoso JC, van Damme P, van Deerlin VM, van den Bosch L, Zinman L, Tienari PJ, Stone DJ, Nalls MA, Singleton AB, Chiò A, Traynor BJ (2019) Shared polygenic risk and causal inferences in amyotrophic lateral sclerosis. Ann Neurol 85:470-481. https://doi.org/10.1002/ana.25431

84. Ahmed RM, Dupuis L, Kiernan MC (2018) Paradox of amyotrophic lateral sclerosis and energy metabolism. J Neurol Neurosurg Psychiatry 89:1013-1014. https://doi.org/10.1136/jnnp-2018318428

Publisher's note Springer Nature remains neutral with regard to jurisdictional claims in published maps and institutional affiliations. 